\title{
INTROGRESSION IN WHEAT VIA TRIPLOID HYBRIDS*
}

\author{
ALIZA VARDI and DANIEL ZOHARY \\ Deportment of Botony, the Hebrew University, Jerusolem, Isroel
}

Received 24.xii.66

\section{INTRODUCTION}

IN several recent papers (for review see Zohary, I965), the hypothesis was advanced that the apparent evolutionary success of polyploid entities in the wheat group (Triticum and Egilops) was largely dependent on introgression. It was assumed that these polyploids were able to evolve rapidly and successfully colonise new habitats because their chromosome system had the advantage of being well buffered to absorb alien genetic material. It was demonstrated (Zohary and Feldman, 1962; Feldman, 1965; Pazy and Zohary, 1965) that Egilops polyploids are not simple amphidiploids. Hybridisation between amphidiploids sharing a common genome was found to be a regular device for generating variation and ensuring genetic flexibility.

The present paper aims to demonstrate that additional sources of variation are present in the wheat group-which supplement the polyploid-to-polyploid gene transfer previously described. This work deals with direct introgression from diploids to tetraploids via triploid bridges. The process has been studied in two representative species combinations: by examination of the interspecific triploid hybrids and the types of $F_{2}$ and $F_{3}$ progenies they produced.

\section{METHODS}

Meiosis in p.m.c.s served both for determination of chromosome numbers and for the study of chromosome pairing. Anthers were fixed in 3:I alcohol-acetic acid for 24 hours, stored in 70 per cent. alcohol and stained in acetocarmine.

Since chromosome numbers varied from plant to plant, pairing is expressed as " associations per chromosome" and not "chiasmata per cell". In each plant this value is based on only four randomly picked metaphases. Only in the triploids themselves and in the $F_{2}$ parents of the $F_{3}$ families samples of 30 cells were employed. We found that with the large number of chromosomes present (27-35), variation in chiasmata numbers between cells within plants was relatively small; and the sampling error due to samples of only four cells negligible for the purpose of the present work.

Pollen fertility was determined by dissecting mature anthers soaked in 4 per cent. acetocarmine and scoring c. 500 pollen grains per plant. Grains were considered normal when they were rounded and well stained.

Seed fertility was determined by examination of the two lower florets in the spikelet. A floret was considered fertile if a well-developed kernel was found in it. In the case of more fertile plants a sample of roo florets (i.e. 5o spikelets) was employed. In the semi-sterile plants, and particularly in the triploids themselves, seed set was determined by examination of all available spikes.

* The material presented in this paper comprises a part of the Ph.D. thesis work of A. Vardi, to be presented to the Hebrew University, Jerusalem. 


\section{PRELIMINARY INDICATIONS}

The following observations indicated to us the operation in nature of direct diploid to polyploid introgression.

First spontaneous triploid hybrids were repeatedly encountered. This was the case in mixed diploid-polyploid stands in Israel as well as in adjacent countries and in several species combinations. Although spontaneous triploids are very rare (estimated frequencies are in the order of $\mathrm{IO}^{-4}$ to $\mathrm{IO}^{-5}$ ), one could repeatedly detect them in contact places by methodical screening. Representative mixed populations in which such triploid hybrids were detected were tetraploid \#gilops variabilis with diploid $\not E$. sharonensis or diploid $A$. longissima (Israeli coastal plain); tetraploid $E$. kotschyi with diploid $A$. longissima (Israeli Negev); tetraploid $\mathcal{T}$. durum with diploid $A$. longissima (Israel); tetraploid $\mathcal{T}$. durum (as well as hexaploid $T$. estivum) with diploid $\mathcal{T}$. bxoticum (Turkey, Iran).

Another clue came from the realisation that triploid interspecific hybrids were not fully sterile. In I $962-6_{5}$ several triploids of different species combinations were grown in the Jerusalem nursery. All these $\mathrm{F}_{1}$ hybrids were completely male sterile, their anthers did not dehisce. But when exposed to a mass of parental pollen, the majority of the triploid plants did set rare back-cross seed.

Finally indications of diploid to polyploid gene-flow came from the examination of variation patterns in mixed diploid-polyploid stands. In several species combinations characteristic introgressive hybridisation variation patterns were apparent among the polyploid plants-or trends to "mimic" the diploid partners were observed. Thus in southern Turkey tetraploid $T$. diciccoides was found to "approach" diploid T. bxoticum. A similar trend was observed in tetraploid $E$. trinuncialis in the Iranian Zagros range. When mixed with diploid $\not E$. caudata it tends to "mimic" this diploid. When growing with diploid $\not E$. squarrosa it sometimes shows characteristic squarrosa-like rachis disarticulation. In one case, namely of tetraploid $A E$. variabilisdiploid $A$. longissima in Israel mixed stands near Ashkelon were found to contain not only triploid interspecific hybrids but also semi-sterile plants intermediate in their morphology between the $F_{1}$ triploids and typical $2 E$. variabilis.

\section{EXPERIMENTAL PROCEDURES AND RESULTS}

The following two interspecific triploid combinations were selected for analysis. (For details on genomic formulation in the wheat group consult Kihara, I 954, and Sears, I 959.)

(i) tetraploid Triticum durum (AABB)

(ii) tetraploid Triticum durum (AABB)

$\times$ diploid Triticum broticum (AA).

$\times$ diploid Agilops longissima $\left(\mathrm{S}^{\mathrm{l}} \mathrm{S}^{\mathrm{l}}\right)$. 
These two combinations present the two main classes of interspecific triploid hybrids encountered in the wheat group. They differ markedly from one another in the degree of chromosome pairing:

Triploid combination (i) is genomically $\mathrm{AAB}$ and contains two sets of more or less homologous chromosomes. This is a case of closely related diploid and tetraploid species, where one of the durum genomes (genome A) is similar to the chromosome set of diploid wild einkorn.

Triploid combination (ii) is $\mathrm{ABS}^{1}$. It thus contains three different sets of chromosomes and shows very little chromosome pairing in meiosis. This combination is representative of cases where the diploid species is not directly related to the tetraploid one and apparently did not participate in its amphidiploid formation.

These artificial $F_{1}$ triploid hybrids were grown in Jerusalem in 1963. They were planted intermixed with the tetraploid wheat and were isolated from any other Triticum or Egilops species. Thus the male sterile triploids were massively exposed to (back-cross) pollination by their tetraploid wheat parent. The occasional, rare back-cross seeds produced by the triploids were planted in 1964 and the second generation of hybrid derivatives was grown and analysed. These $F_{2}$ plants were also interplanted with tetraploid wheats. But since some of them were already semi-fertile, the seed they produced were a mixture of selfed and second back-cross products. Selected families of third hybrid generation derivatives were grown in 1965 . The following diagram sketches the experimental design employed.

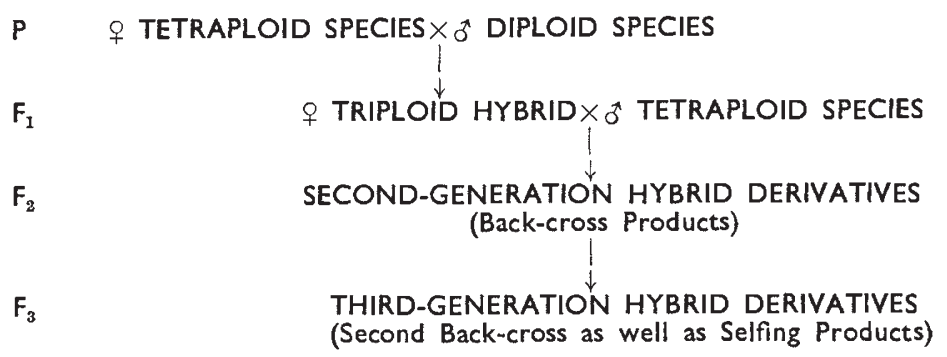

The results obtained are described in the following two sections.

(i) AAB triploid combination T. durum $\times$ T. bœoticum

(a) $F_{1}$ hybrids

The four T. durum $\times T$. broticum triploids (genomic constitution $\mathrm{AAB}$ ) showed marked vegetative vigour under Jerusalem nursery conditions and exceeded both parental lines in height and in number of tillers produced. Each produce 25-40 well-developed flowering spikes. Meiosis in the four plants was uniform and showed the characteristic features of wheat triploids where one genome is found in double dose: from four to seven bivalents (see plate III, fig. I) and occasionally also a single trivalent. Pollen abortion was 98-99 per cent. and subsequently anthers did not dehisce. Thus the triploids were 


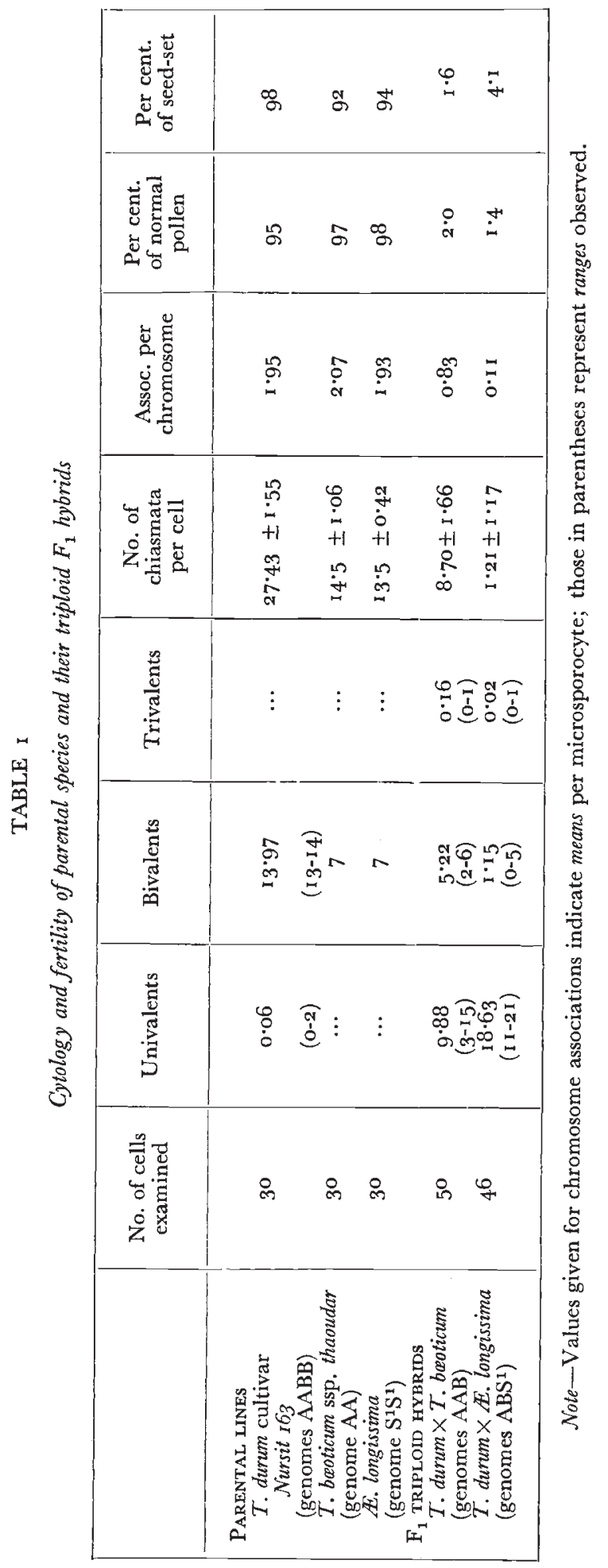


completely male sterile. Pollination was assured by surrounding tetraploid wheat plants. The four vigorous triploids with their dozens of ears produced 2700 well-developed spikelets and 99 back-cross seed (table I).

\section{(b) Second-generation hybrid derivatives}

The $\mathrm{F}_{2}$ generation was started by planting the (back-cross) seed secured from the durum $\times$ bocoticum triploids.

Growth and development. A wide range of variation in germination, development and vigour was noted. Several kernels failed to germinate or develop, but the majority of individuals (75 altogether) reached maturity. Many showed pronounced vigour and even exceeded the original parental lines in size and development. Morphologically the larger proportion of the plants resembled the tetraploid wheat parent both in their erect habit and the shape of their ears (plate I).

Cytology. Chromosome numbers in the progeny of the durum $\times$ beoticum triploids ranged from 27 to 30 with the mode of 28 (table 2). All these numbers are higher than the mode of $24-25$ chromosomes expected from a random segregation in a triploid $(2 n=2 \mathrm{I}) \times$ tetraploid $(2 n=28)$ cross.

A striking improvement in chromosome pairing was apparent in the progeny when compared with their triploid parents. This is reflected in the frequency distribution of associations per chromosome (Plate III). Significantly, 45 of the $5^{\mathrm{I}} \mathrm{F}_{2}$ plants were characterised by a predominance of cells with I 2-I 3 and sometimes even I4 bivalents (including occasional trivalents) plus 2-6 univalents. Moreover, most of the bivalents observed were of the ring type. Thus in general terms, the $\mathrm{F}_{2}$ plants demonstrated pairing in $24-28$ of their $27-30$ chromosomes (table 3 , figs. 2 and 3 ).

The cytological information on the $\mathrm{F}_{2}$ generation also indicates what types of viable products the $\mathrm{AAB} \mathrm{F}_{1}$ triploids are able to produce. Pollen for the formation of all $\mathrm{F}_{2}$ plants was standard, namely $n=14$ $\mathrm{AB}$ durum pollen. Since the majority of the $\mathrm{F}_{2}$ plants (with their 27-30 chromosomes) showed prevalence of 12 to 14 bivalents, they should have inherited, from their maternal $\mathrm{AAB}$ triploid parent, two more or less full chromosome sets ( $13^{-16}$ chromosomes), one of genome $\mathrm{A}$ and one of $\mathrm{B}$. Thus the predominance in the $\mathrm{F}_{2}$ generation of plants with 28-29 chromosomes apparently reflects a mechanism of genomic buffering (see Discussion).

Fertility. Parallel to the improvement in chromosome pairing remarkable restoration of fertility is apparent in the durum $\times$ beoticum second-generation plants. This is true both for pollen scores (table 4) and for seed fertility (table 5). A wide variation in pollen and seed set was observed between plants, and individuals ranged from almost sterile to fully fertile. But significantly 69 out of $72 \mathrm{~F}_{2}$ plants showed more than 5 per cent. of normally stained pollen-and their anthers at least partly dehisced. Moreover, several plants showed normal $2 \mathrm{M}$ 


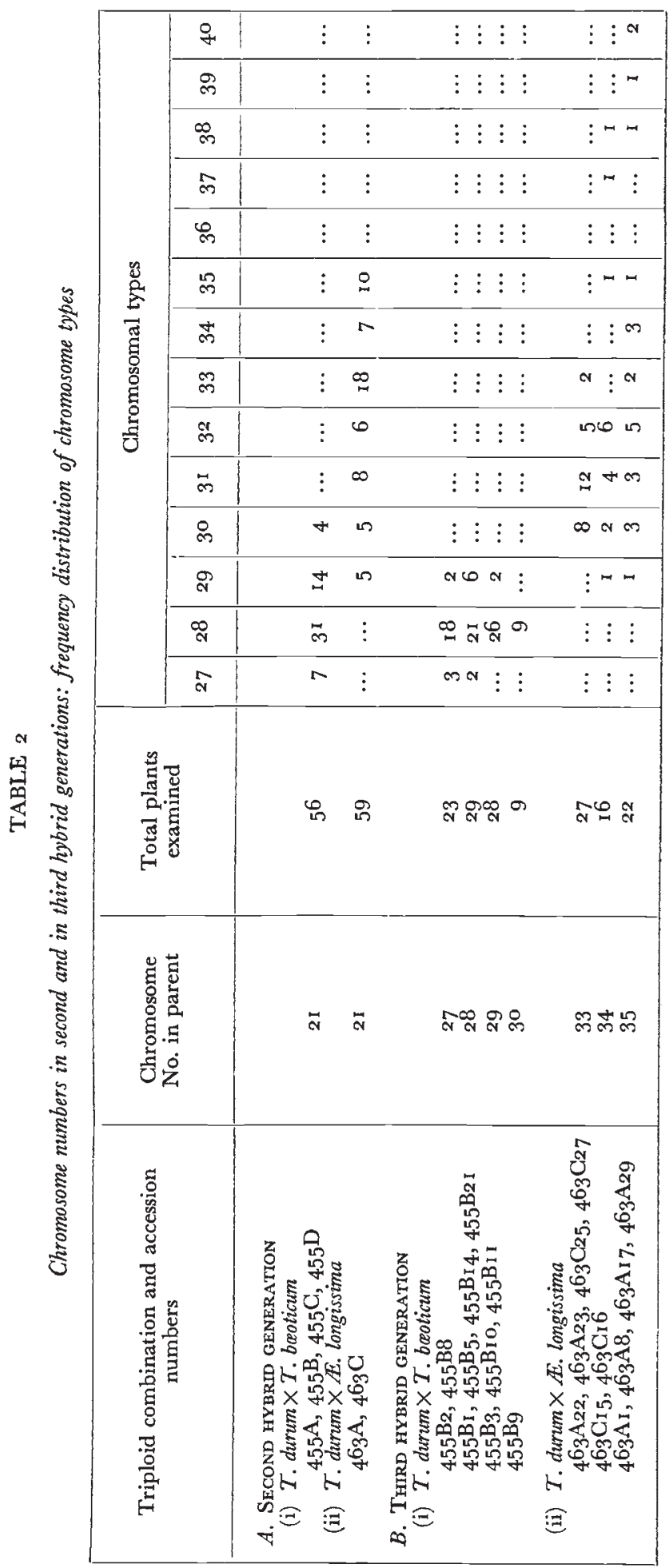




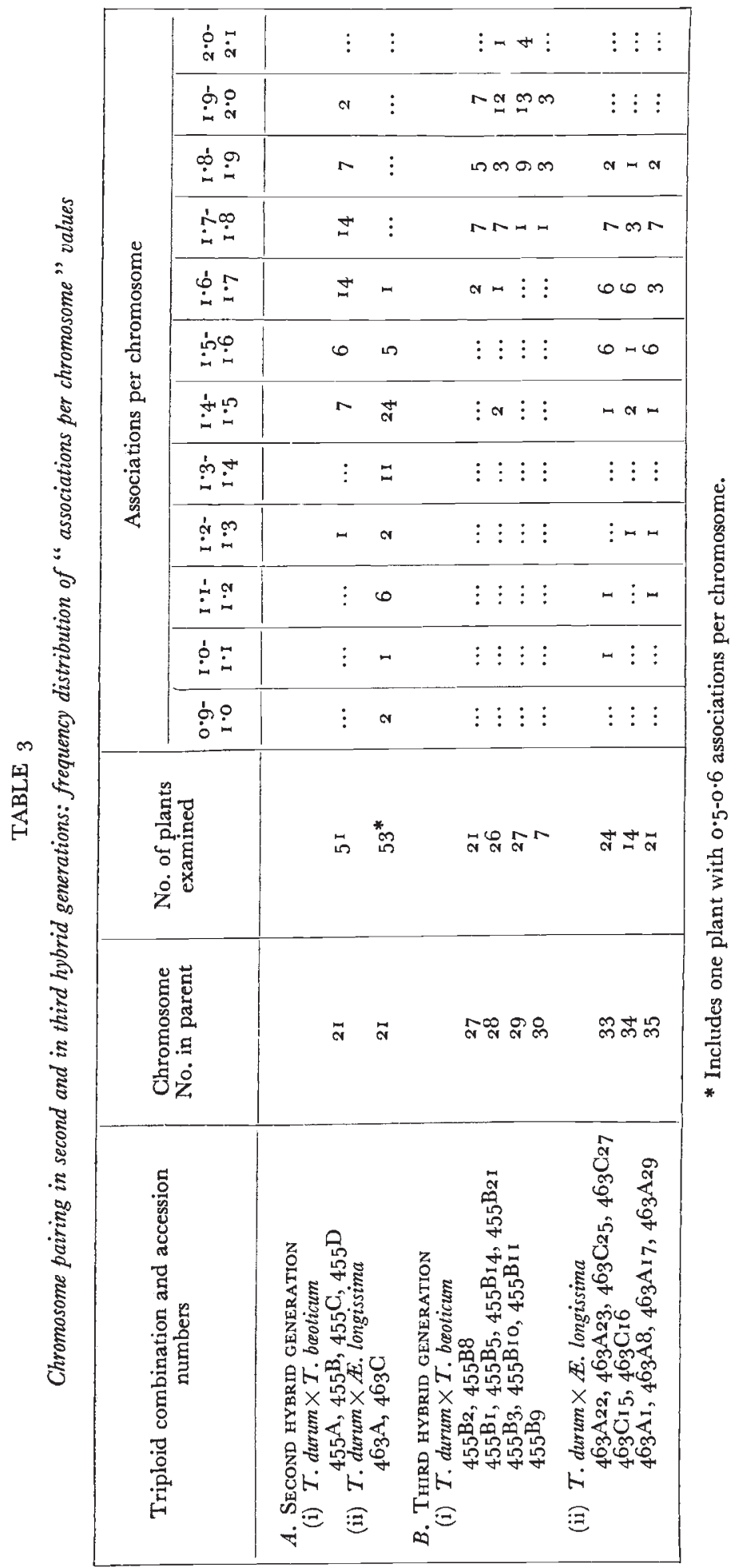


or almost normal pollen fertility. The restoration is obvious also from the seed set data (table 5): the majority of the individuals were semifertile and some showed 75-Ioo per cent. seed set. A rough correlation between bivalent formation and fertility was noted. Plants with prevalence of $13-14$ bivalents tended to be more fertile. This was particularly true in $2 n=28$ plants.

\section{(c) Third-generation hybrid derivatives}

Ten representative families of third-hybrid generation plants of the durum $\times$ bxoticum combination were raised. Each $\mathrm{F}_{\mathbf{3}}$ family consisted of a sample of I 3 -I 5 progenies grown from seed produced by an individual $\mathrm{F}_{2}$ plant. Two such $\mathrm{F}_{3}$ families were derived from $2 n=27$ parents, four from $\mathrm{F}_{2}$ parents with 28 chromosomes, three from parents with 29 chromosomes and the tenth had a $2 n=30$ seed parent (table 6). These parents represent the various chromosome types and fertility classes of the second hybrid generation of the durum $\times$ booticum combination. They all showed some degree of pollen fertility with anthers at least partly dehisced. Since the ten parents were also exposed to pollen of tetraploid wheats, the $\mathrm{F}_{3}$ generation should be considered as a mixture of selfed products and second back-cross derivatives.

Growth and development. All $\mathrm{F}_{3}$ families were strikingly similar to the tetraploid wheat parent. With the exception of 3-4 freaks, plants showed normal development. Segregation occurred both between and within families, in characters such as vegetative vigour, shape of spikes, brittleness and hairiness. The majority of the individuals in all ten families were vegetatively vigorous, many even taller than their tetraploid durum parent, and produced large, long ears.

Cytology. Chromosome numbers in the $\mathrm{F}_{3}$ representatives varied from 27 to 29 with a conspicuous trend to stabilise the chromosome number at $2 n=28$ (table 2 ). Progenies derived from $2 n=27$ parents increased their chromosomes: 18 out of the 23 progenies examined had $2 n=28$. Progenies from $2 n=28$ parents remained centred around their parents' number, while of those from $2 n=29$ and $2 n=30$ parents all but two had 28 chromosomes.

A general trend for further improvement in chromosome pairing characterises all the ten $\mathrm{F}_{\mathbf{3}}$ durum $\times$ beoticum families. Chromosome association in the majority of plants was almost normal, particularly in the $2 n=28$ derivatives. More than half of the $2 n=28$ plants commonly had I3-14 bivalents, and only occasional univalents. Some showed regular formation of I4 bivalents (see plate III, fig. 4) and were similar in chromosome behaviour to the original tetraploid durum stock. This improvement in chromosome pairing is reflected in the associations per chromosome (table 3 ). Most $\mathrm{F}_{3}$ individuals scored values higher than their $\mathrm{F}_{2}$ parents and very few scored less. Forty out of the 8I plants had values higher than $I \cdot 9$ (means of $26-29$ chiasmata per p.m.c.), and thus entered the normal range of chromosome pairing found in the tetraploid durum wheat. 


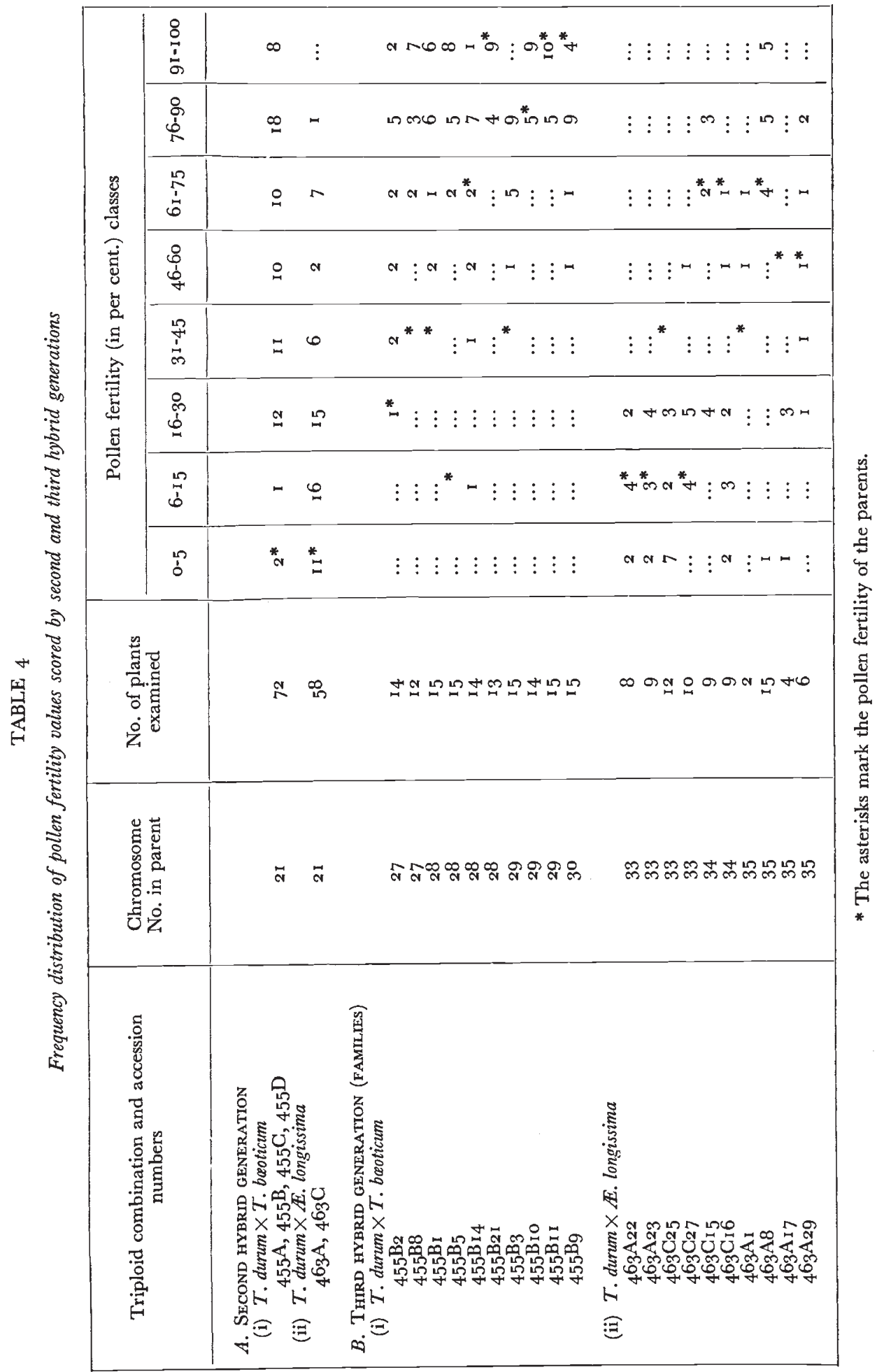


A. VARDI AND D. ZOHARY

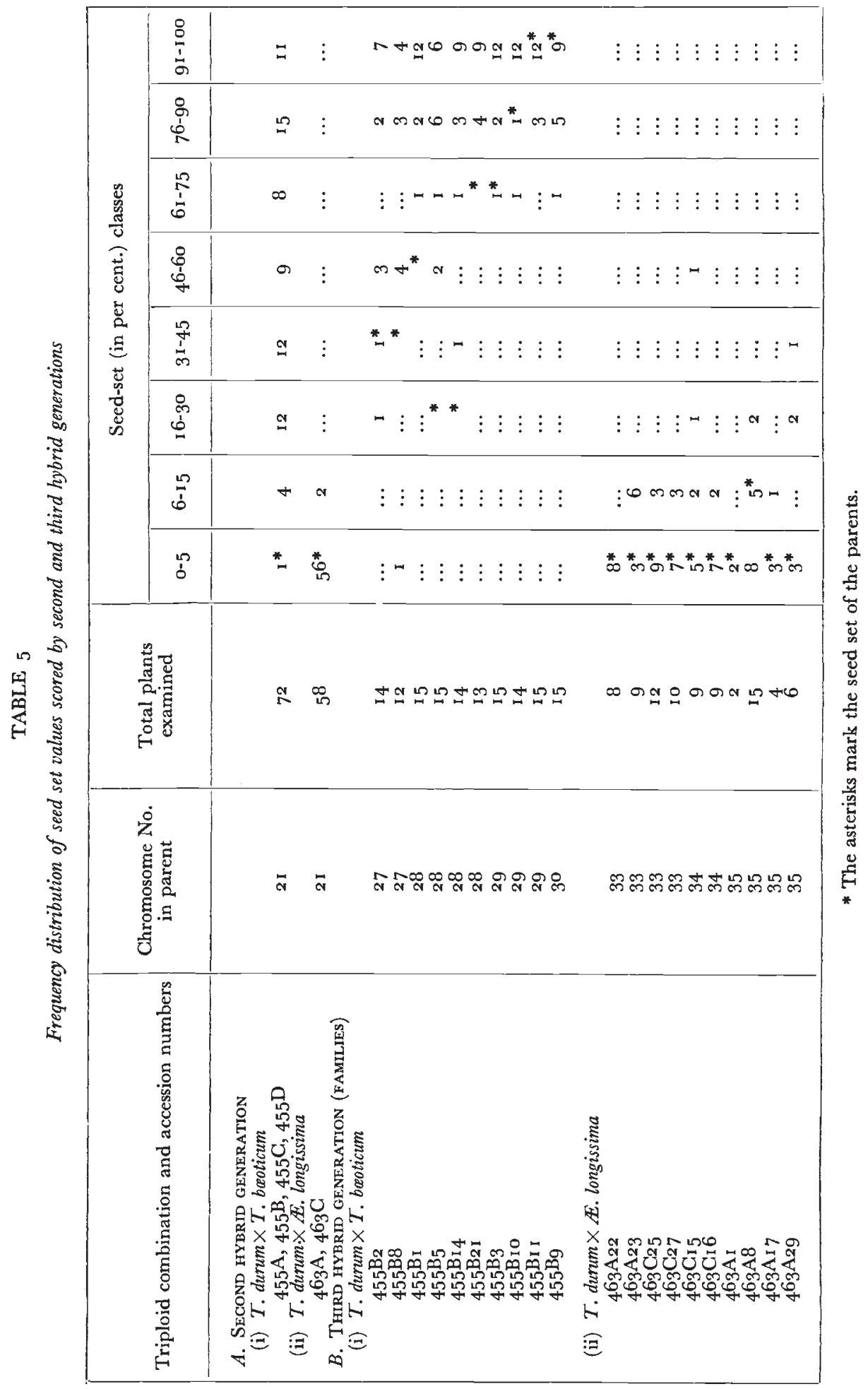




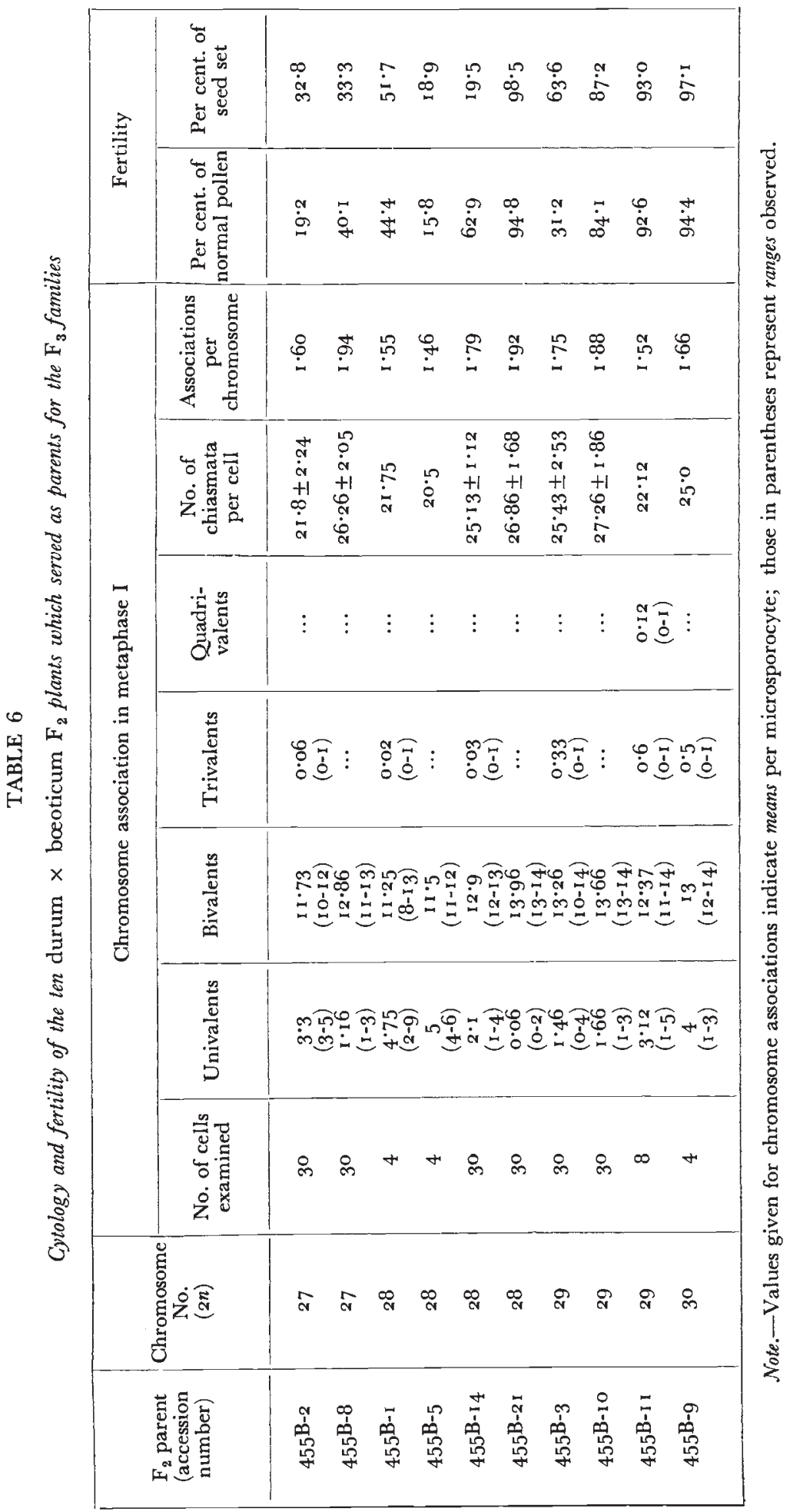


Thus, in all the ten representative $\mathrm{F}_{3}$ families of the durum $\times$ bcoticum combination there is a marked trend for stabilisation of chromosome number at the euploid tetraploid level. Moreover, many individuals already show a pattern of chromosome pairing characteristic of the tetraploid durum parental stock.

Fertility. Parallel to the trend for chromosome stabilisation just described, further improvement of fertility occurs in all the ten $F_{3}$ families (tables 4 and 5). In fact, the larger proportion of the thirdgeneration plants were found to be fully fertile or almost fully fertile.

\section{(ii) $A B^{1}$ triploid combination (T. durum $\times \mathbb{E}$. longissima)}

\section{(a) $F_{1}$ hybrids}

The two $T$. durum $\times$ E. longissima triploids (genomic constitution $\mathrm{ABS}^{1}$ ) showed conspicuous vegetative vigour under Jerusalem nursery conditions; each produced numerous tillers and dozens of long, welldeveloped spikes. Meiosis in both plants was characteristic of wheat triploids containing three different genomes. There was very little chromosome pairing (table r). Most common were p.m.c.s with a single-rod bivalent plus I9 univalents (plate III, fig. 5); cells with 2 I I or $2 \mathrm{II}+\mathrm{I} 7 \mathrm{I}$ were also rather frequent. Chiasmata per cell values were thus very low-around $\mathrm{I} \cdot 2$. At the end of first meiotic division 2-4 per cent. of the cells contained restitution nuclei. Such nuclei, with the full set of $2 \mathrm{I}$ elements, were apparently formed in p.m.c.s which previously contained univalents only (plate III, fig. 6). In addition, cells with almost complete restitution nuclei were also frequent. The latter apparently have been produced by cells with a single bivalent which many times showed at the end of the first division a restitution aggregate of univalents at their centre, while the bivalents' separating products were paradoxically excluded as micronuclei at the poles (plate III, fig. 6). Similar to the $\mathrm{AAB}$ combination, the $\mathrm{ABS}^{1}$ triploids were fully male sterile. Anthers did not dehisce and contained only $\mathrm{I} \cdot \mathrm{O}-\mathrm{I} \cdot 5$ per cent. of stainable pollen. But plants were massively exposed to pollen of tetraploid wheat and produced 2-4 per cent. of back-cross seed.

\section{(b) Second-generation hybrid derivatives}

The $\mathrm{F}_{2}$ generation was started by planting the (back-cross) seed secured from the durum $\times$ longissima triploids.

Growth and development. A very wide range of variation in germination, development and vegetative vigour was noted. Sixty seeds were planted and all but one reached maturity. Wide morphological segregation was apparent, and in contrast to the durum $\times$ bæoticum case many $F_{2}$ plants had a "wild type" appearance, i.e. spreading or semispreading habit and very elongate, cylindrical or loose spikes. Some even showed the strong terminal awns characteristic of the longissima spike (plate II). 
Cytology. The $\mathrm{F}_{2}$ generation from durum $\times$ longissima had chromosome numbers ranging from 29 to 35 , with a majority (35 out of 53) containing 33-35 chromosomes. These values are higher by 5-7 chromosomes than those found in the progeny of the previous durum $\times$ beoticum combination.

$\mathrm{F}_{2}$ plants showed remarkable improvement in chromosome pairing compared to their $\mathrm{F}_{1}$ parents, but also varied widely in this character. Most plants, however, showed a high frequency of univalents (7-12) and many (40 out of 53) had 9-14 bivalents (including occasional trivalents). Moreover, bivalents were mainly of the ring type (plate III, figs. 7 and 8). Thus the major difference between the $F_{2}$ from the $\mathrm{AAB}$ combination and that from the $\mathrm{ABS}^{1}$ combination was not in the number of paired chromosomes present, but in the additional univalents present in the $\mathrm{ABS}^{\mathbf{1}}$ derivatives. This was particularly conspicuous in pentaploid or almost pentaploid $\mathrm{F}_{2}$ individuals. It is also reflected in the " associations per chromosome" scored by the durum $\times$ longissima $\mathrm{F}_{\mathbf{2}}$ plants (table 3 ). The lower values of the ABS derivatives are mainly due to the presence of additional univalents, not the lack of bivalents. In mean chiasmata per cell, $\mathrm{F}_{2}$ progenies from durum $\times$ longissima scored values only slightly lower than those of their durum $\times$ booticum counterparts.

The cytological data assembled enabled conclusions to be drawn on the types of viable gametes produced by the $\mathrm{ABS}^{1}$ triploids. The pollen source was standard, and all $\mathrm{F}_{2}$ plants resulted from back pollination by $n=\mathrm{I} 4 \mathrm{AB}$ durum pollen. Since the larger part of viable $\mathrm{F}_{2}$ plants were pentaploid or almost pentaploid (33-35 chromosomes), the most frequent class of viable female gametophytes (or gametophytes that gave rise to viable zygotes) produced by the $\mathrm{ABS}^{1}$ triploid were those with unreduced or almost unreduced nuclei. That pentaploid $\mathrm{F}_{2}$ plants had actually a rough $\mathrm{AABBS}^{1}$ constitution is shown also by the frequent occurrence of 14 bivalents +7 univalents (plate III, fig. 8). Thus, in this combination also the operation of genomic buffering is apparent; but in this case largely gametophytes with approximately three full sets of chromosomes have survived.

Fertility. In contrast to the semi-fertility of the durum $\times$ broticum derivatives most of the $\mathrm{F}_{2}$ plants from the durum $\times$ longissima were almost sterile (tables 4 and 5 ).

\section{(c) Third-generation hybrid derivatives}

Ten $\mathrm{F}_{3}$ families from the durum $\times$ longissima combination were raised and each family was derived from a single, representative $\mathrm{F}_{2}$ plant. Some of these families are smaller than those in the previous (durum $\times$ bœoticum) combination. This was determined by the lower fertility of the $\mathrm{F}_{2}$ generation mentioned above. The parents of the $\mathrm{F}_{3}$ families were selected to represent the common chromosome types and fertility classes encountered in the $\mathrm{F}_{2}$ generation. Four families are derived from parents with $2 n=33$ chromosomes, two from parents 


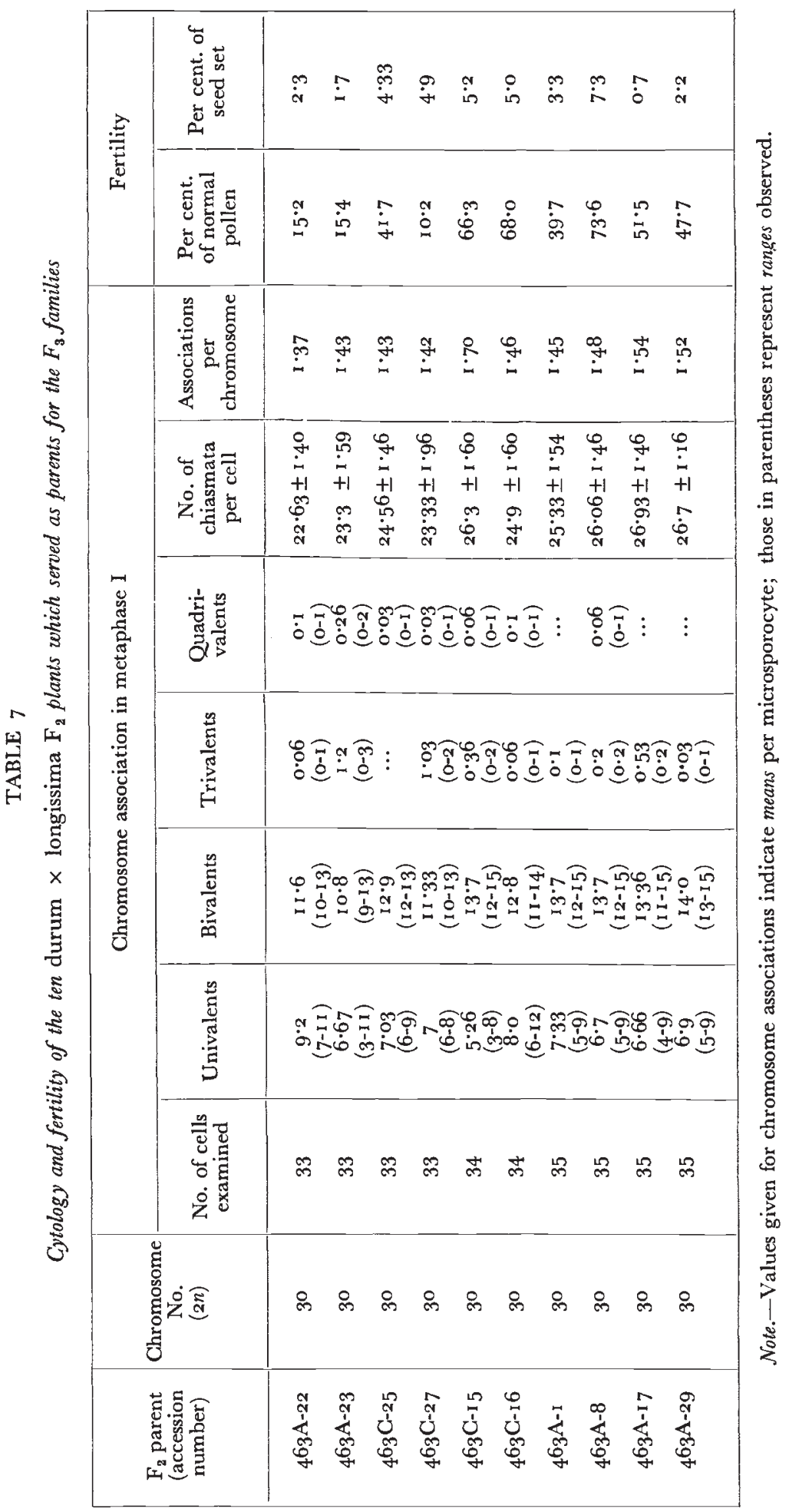


with $2 n=34$ and four from parents with the pentaploid $2 n=35$ (table 7).

Growth and development. $\quad \mathrm{F}_{3}$ plants were much closer in their general morphology to the tetraploid wheat parent than the $F_{2}$ generation. But less so than the $\mathrm{F}_{3}$ generation of the durum $\times$ beoticum combination. Variation was wider here, both within and between families in morphology and in vegetative vigour. Several (7-8) individuals (in several families) were retarded in their growth, while many were quite vigorous, some even exceeded their durum parent in size. Segregation was also noted in habit. About one-third of the plants were erect, the others were semi-spreading or spreading. The genetic contribution of the diploid $E$. longissima was still obvious, particularly in the shape of the ear. More than half of the $\mathrm{F}_{3}$ plants had loose or semi-cylindrical spikes, some were brittle, some were tough.

Cytology. Chromosome numbers in the $\mathrm{F}_{3}$ families varied widely, and individuals from $2 n=29$ to $2 n=4$ o were encountered (table 2 ). In the four $\mathrm{F}_{3}$ families derived from parents with $2 n=33$ there is a trend to decrease in chromosome numbers and the families show mean values some 2-3 chromosomes fewer than their respective $F_{2}$ parents. Thus these four families seem to follow the same trend towards stabilisation at the 28 chromosome level characteristic of the durum $\times$ brooticum combination, although in this case stabilisation has not yet been achieved.

The $F_{3}$ families raised from the pentaploid $(2 n=35)$ or almost pentaploid $(2 n=34)$ parents show a somewhat different picture. Here two trends are apparent. There is an obvious major trend to decrease chromosome numbers parallel to that in the previous four families. But there is also a trend to increase chromosomes since five individuals had chromosome numbers ranging from $3^{8}$ to $4^{\mathrm{o}}$. Moreover, the distribution of chromosome types among $F_{3}$ individuals seems bimodal (table 2).

Compared to their $\mathrm{F}_{2}$ parents, plants of the $\mathrm{F}_{3}$ families showed some improvement in chromosome pairing. This is apparent from the frequency distribution of "associations per chromosome" scored (table 3). However, parallel to the situation in $F_{2}$ the $F_{3}$ plants lag in their scores behind those of the durum $\times$ bxoticum $\mathrm{F}_{3}$ sample. The large majority of plants in all to families were slightly more regular in the formation of ring bivalents than their $\mathrm{F}_{2}$ parents. The majority of $\mathrm{F}_{3}$ plants with 29-32 chromosomes showed prevalence of $\mathrm{I}_{2}-\mathrm{I}_{4}$ bivalents, while $I_{5}-18$ bivalents were common in $F_{3}$ plants with $39-40$ chromosomes. One plant with $2 n=40$ even showed p.m.c.s with I9 II + 2 I (plate III, fig. 9).

Fertility. Most $\mathrm{F}_{3}$ plants were very poor in seed set (table 5), and about two-thirds of them scored seed fertility values of 5 per cent. or less. This is in sharp contrast to the predominance of semi-fertile or almost fertile plants in the $\mathrm{F}_{3}$ representatives of the $\mathrm{AAB}$ combination. But even the low values obtained, represent some degree of restoration 
compared to the values obtained in the $\mathrm{F}_{2}$ generation. Significantly a few $F_{3}$ individuals achieved seed set values in the range of $15^{-5} 5^{\circ}$ per cent. Thus there is a general agreement in the $F_{3}$ generation of the $\mathrm{ABS}^{1}$ combination between the cytological data and the fertility scores. $\mathrm{F}_{3}$ plants have not yet reached either full chromosomal stabilisation or full pollen or seed fertility.

\section{DISCUSSION}

The results indicate that in the wheat (Triticum-AEgilops) group, interspecific triploid hybrids can serve as efficient bridges for gene transfer from diploid to tetraploid species. Further, field observations indicate that such introgression actually operates in nature. The data on various triploid hybrids, and particularly on numerous $\mathrm{F}_{2}$ and $\mathrm{F}_{3}$ progenies from two combinations tested also indicate what happens in the critical stages of introgression: how sterility barriers are crossed and how the drastic segregational unbalance is overcome.

Interspecific triploid wheat hybrids are not completely sterile. When massively exposed to parental pollen (as they are in nature) such hybrids set occasional back-cross seed. This was the case when diploid and tetraploid species shared a common genome (the AAB combination of $T$. durum $\times \mathcal{T}$. beeticum). It was also true when three different genomes constituted the triploid (the $\mathrm{ABS}^{1}$ combination of $T$. durum $\times A$. longissima). Thus by virtue of back pollination (by polyploid parents) an intrigression process is effectively initiated.

The choice of two different triploid combinations clarified what actually happens in the critical stage of the introgression process - when the $\mathrm{F}_{2}$ generation is formed. The large samples of $\mathrm{F}_{2}$ plants examined in each combination show what products escape the segregational "shock", when meiosis in the $F_{1}$ triploids drastically disrupts the original chromosome complements. Similar to the process of tetraploidto-tetraploid introgression in AEgilops (Pazy and Zohary, 1965) the operation of genomic buffering is apparent here. This is reflected by the high chromosome numbers encountered in $\mathbf{F}_{\mathbf{2}}$ plants. It is mainly gametophytes possessing an approximately full chromosome complement which are able to survive or form viable $\mathrm{F}_{2}$ zygotes. From the data gathered the following picture emerges:

(i) In the $\mathrm{AAB}$ combination introgression is apparently effectively initiated by the survival of $13-16$ chromosome, roughly $A B$ female gametophytes. That such gametophytes, possessing more or less the full content of $\mathrm{A}$ and $\mathrm{B}$ genomes, are the main viable products of the $\mathrm{F}_{1}$ triploids is clearly indicated by the chromosome numbers of the $\mathrm{F}_{2}$ plants and the pairing they show (see p. 545). Moreover, the recovery of such $\mathrm{F}_{2}$ segregants is in full accord with the meiotic behaviour of the triploid parents themselves. The two sets of genome A chromosomes form mainly bivalents; this leads to more or less regular A:A separation in anaphase I. Irregular separation is the lot of the single 
B set chromosomes which occur mainly as univalents. From the mode of anaphase distribution of the univalents one expects a small fraction of meiotic segregants incorporating 6-7 B genome chromosomes. This fits well with the seed fertility values found in the AAB triploids. When such essentially $\mathrm{AB}$ female gametophytes are fertilised by standard $n=14 \mathrm{AB}$ durum pollen, stabilisation at the tetraploid level is achieved -and in a single step! This is reflected in the $F_{2}$ generation by the concentration around 28 chromosomes, the conspicuous improvement in chromosome pairing and the spectacular restoration of fertility. What still remains unbalanced is further corrected in the subsequent $\mathrm{F}_{3}$ and $\mathrm{F}_{4}$ generations. But these $\mathrm{F}_{3}$ and $\mathrm{F}_{4}$ corrections (i.e. elimination of I-2 surplus chromosomes, increase from 27 to 28 chromosomes, improvement in pairing, further recovery of fertility) are indeed relatively minor adjustments. All in all gene transfer from diploid T. beoticum to tetraploid T. durum via a triploid hybrid bridge is a neat, basically one-step process. Paradoxically it is well canalised by the high sterility of the triploid, i.e. by the drastic selection which weeds out meiotic products other than the rare, chromosomally balanced AB-type female gametophytes. When stabilisation is attained and fertility restored, selection coupled with self-pollination would rapidly fix favourable recombinations and complete the introgression cycle.

(ii) In the $\mathrm{ABS}^{1}$ combination diploid to tetraploid introgression is obviously a longer process. But here too a mechanism of genomic balancing buffers the critical stage. Examination of $F_{2}$ plants clearly shows that the main class of viable products produced by the $\mathrm{ABS}^{1}$ triploids is that of unreduced or almost unreduced gametophytes. The main difference between the $\mathrm{AAB}$ and the $\mathrm{ABS}^{1}$ combinations is thus in the number of genomes that go together to form viable gametophytes. When one genome is shared, the main likelihood is for two-set $\mathrm{AB}$ products. But when three different genomes combine in the $F_{1}$ hybrid the most common viable products are three-set or almost threeset $\mathrm{ABS}^{1}$ gametophytes. Why triple dosage prevails (rather than balanced products with only two genomes) is indicated also by the meiotic behaviour of the $\mathrm{ABS}^{1} \mathrm{~F}_{1}$ triploids. In contrast with $\mathrm{AAB} \mathrm{F}_{1}$ triploids one finds here almost no chromosome pairing (see p. 552). Subsequently restitution nuclei with 33-35 chromosomes are regularly produced-in the order of few per cent. On the other hand, when 2 I univalents are present, the chance for segregation of more or less two full sets is very small indeed.

When such roughly $\mathrm{ABS}^{1}$ constituted female gametophytes are fertilised by $n=14$ durum $\mathrm{AB}$ pollen the resulting $\mathrm{F}_{2}$ generation is mainly pentaploid or near pentaploid, and stabilisation is a much longer process. In contrast with the $\mathrm{F}_{2}$ generation of the previous combination, $F_{2}$ plants here are yet largely sterile. Even the $F_{3}$ families contain mostly unbalanced products, but improvement is apparent. There is a main trend among $F_{3}$ individuals to decrease chromosome numbers and restore fertility. Significantly $\mathrm{F}_{3}$ individuals 
with 29-33 chromosomes include semi-fertile plants, many of which are characterised already by the prevalence of $\mathrm{I}^{-\mathrm{I}} 4$ bivalents. Future development seems to be determined. Such semi-fertile plants can be expected to further decrease their chromosome numbers in one or two generations and to become stabilised at the tetraploid $2 n=28$ durum level. That such products could easily incorporate alien substitution segments donated by the $\mathrm{S}^{1}$ genome is indicated by the occurrence of trivalents both in the $F_{1}$ and $F_{2}$ generations. Moreover, the stabilisation process might be further hastened by additional back-cross pollination of either the $\mathrm{F}_{2}$ or the $\mathrm{F}_{3}$ plants. All in all, one is led to the conclusion that gene transfer from diploid $E$. longissima to tetraploid $\mathcal{T}$. durum via a triploid bridge can be achieved in a matter of 3-4 generations. It is not a quick one-step process, as the previous bridge was. Yet it is relatively efficiently achieved and well buffered, in its critical stage, by $\mathrm{F}_{2}$ pentaploidy.

Apart from the $\mathrm{F}_{2}$ trend to decrease chromosome numbers toward stabilisation at the $2 n=28$ durum level, the $\mathrm{ABS}^{1}$ combination $\mathrm{F}_{3}$ plants indicate an alternative development of chromosome increase. This trend is clear in the families obtained from pentaploid, $2 n=35$ AABBS $^{1} \mathrm{~F}_{2}$ individuals. $\mathrm{F}_{3}$ families of such $2 n=35$ parents show bimodal distribution of chromosome numbers (table 2) and chromosome numbers as high as 40 . One $\mathrm{F}_{3} 2 n=40$ plant showed I9 bivalents +2 univalents. Such $\mathrm{F}_{3}$ individuals might lead to fixation at the hexaploid level and give rise to a new, $2 n=42, \mathrm{AABBS}^{1} \mathrm{~S}^{1}$ amphidiploid. More data are needed before this trend of chromosome increase could be critically evaluated. But even at this stage one is tempted to suggest that hexaploid entities in Triticum and Egilops could have originated in such a fashion, and are not necessarily exclusively products of somatic chromosome doubling in triploid $\mathrm{F}_{\mathbf{1}}$ hybrids. If so, hexaploid cultivated wheat T. astivum could have evolved in a similar way-upon back-pollination of a tetraploid wheat $\times A$. squarrosa spontaneous hybrid. Such ABD triploid could have given rise to a AABBD $\mathrm{F}_{2}$ pentaploid. This in turn could have produced a stabilised AABBDD amphidiploid.

As to the actual evolutionary role of diploid to tetraploid introgression in variation build-up in polyploid Triticum and Aegilops species-it is yet difficult to arrive at any definite evaluation. Our main aim in this paper is to point out the fact that such gene-flow is possible and could have added significantly to the build up of variation and to the evolutionary success of polyploid entities here. Situations like $\not E$. variabilis- $\not E$. longissima clearly indicate its occurrence in nature. But from our experience with Egilops and Triticum species in the Middle Eastern countries it seems that diploid to tetraploid connections are far less frequent than connections between the tetraploids themselves. Only the later interconnections (see Zohary, 1965) are very frequent and conspicuous in nature. Yet one has also to bear in mind that when a common genome is shared by the diploid donor and the tetraploid 


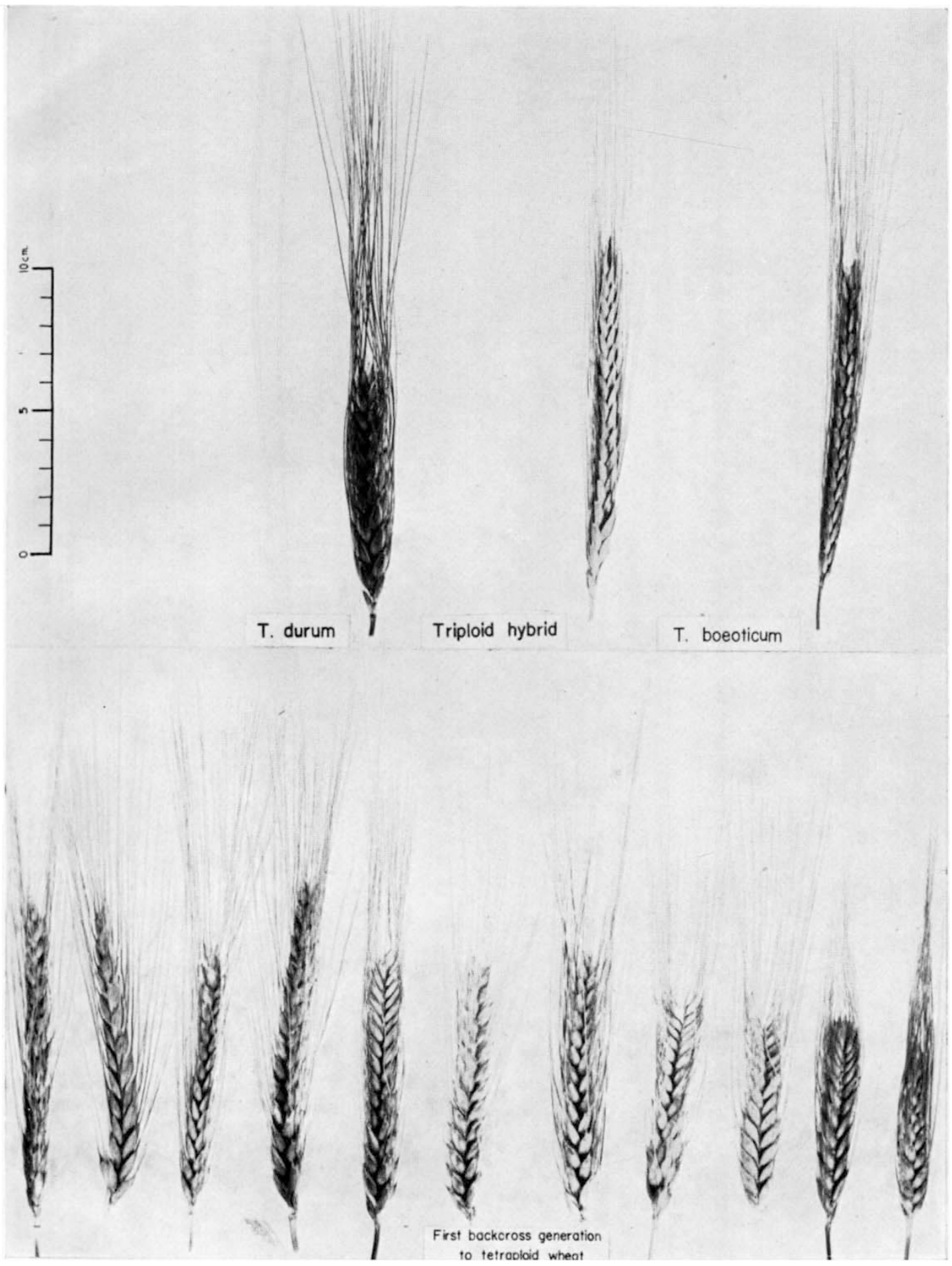

Representative spikes from the parental species, $F_{1}$ triploid hybrid and $F_{2}$ derivatives in $T$. durum $\times$ T. beoticum AAB combination. Note the close morphological resemblance of the $\mathrm{F}_{2}$ plants to their durum parent. 


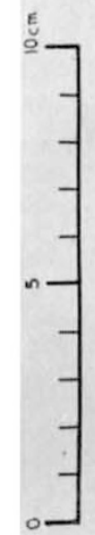

T. durum

Triploid hybrid

Ae. Iongissima
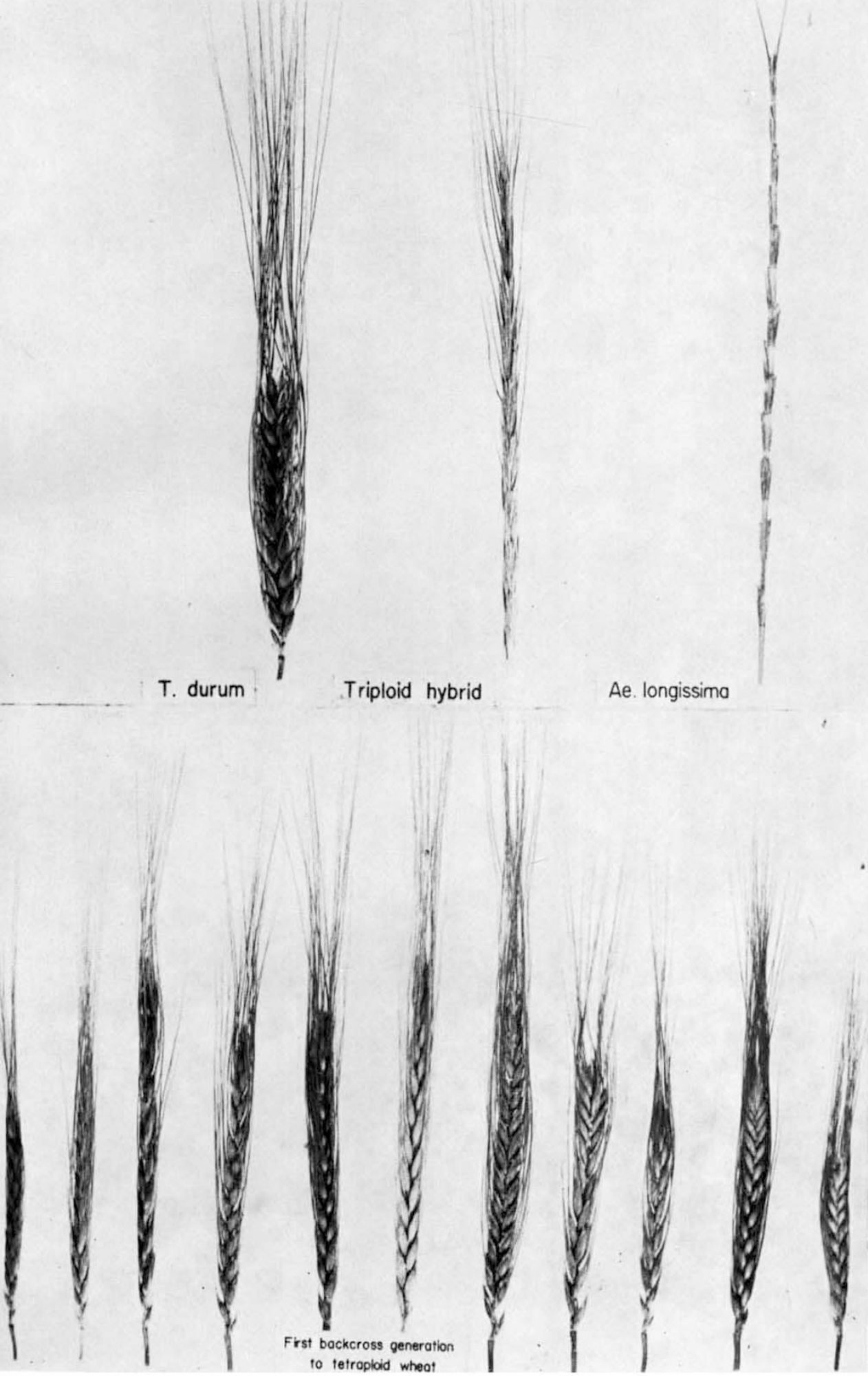

Representative spikes from the parental species $F_{1}$, triploid hybrid and $\mathrm{F}_{2}$ derivatives in $T$. durum $\times \not$ E. longissima $\mathrm{ABS}^{1}$ combination. Note the wide segregation in the $\mathrm{F}_{2}$ generation. 


\section{Plate III}

FIGS. I-4. Meiosis in durum $\times$ broticum AAB combination.

FIG. I. $-6 \mathrm{II}+9 \mathrm{I}$ in $\mathrm{F}_{1}$ triploid.

FrG. 2.- $-13 \mathrm{II}+2 \mathrm{I}$ in $2 n=28 \mathrm{~F}_{2}$ plant.

FIG. 3. - I 4 II $+\mathrm{I} I$ in $2 n=29 \mathrm{~F}_{2}$ plant.

FIG. 4. - 14 II in stabilised $2 n=28 \mathrm{~F}_{8}$ plant.

FIGS. 5-9. Meiosis durum $\times$ longissima $\mathrm{ABS}^{1}$ combination.

FIG. 5.-I II+ Ig I in $F_{1}$ triploid.

FIG. 6.-Microsporocyte with a full restitution nucleus and microsporocyte with almost full restitution nucleus at the end of first division in the $F_{1}$ triploid.

FIG. 7 - I IV $+8 \mathrm{II}+\mathrm{II} \mathrm{I}$ in $2 n=3 \mathrm{I} \mathrm{F}_{2}$ plant.

Frg. 8.- I $4 \mathrm{II}+7 \mathrm{I}$ in pentaploid $\mathrm{F}_{2}$ plant.

FIG. 9. - I II II 2 I in $2 n=40 F_{3}$ plant.

Magnification: fig. $6 c . \times 300$; all other figs. $\times 750$. 


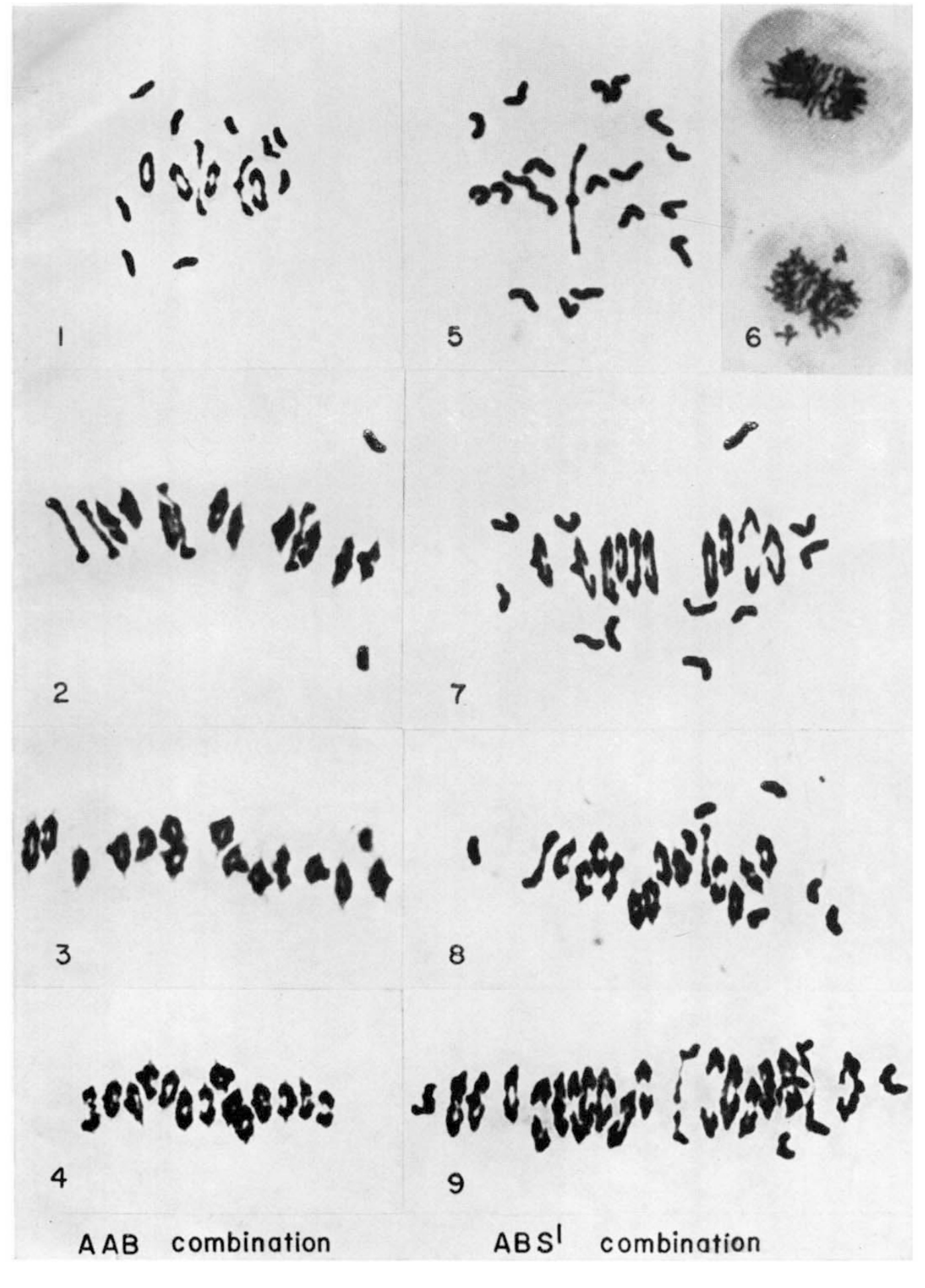


receptor introgression via triploids is not only a quick but, as already noted by Harlan (1964), also a subtle process. While $\mathrm{F}_{1}$ triploids can be detected in natural mixed stands it is very hard to recognise morphologically the $\mathrm{F}_{2}$ derivatives. Thus one can easily overlook such introgression. In addition direct diploid to tetraploid introgression could have played a decisive role in the past, when polyploids were just formed and when it could have greatly assisted their initial spread into areas yet occupied by diploids alone-in a similar way that it did apparently help tetraploids in the Dactylis glomerata complex (Zohary and Nur, 1959) to achieve their distribution.

Finally it seems worth while to suggest some practical applications for the two triploid bridges described. Such experimental design can serve in wheat breeding work. The AAB case can serve as a model for an easy transfer of favourable genes from diploid einkorn or diploid E. speltoides to tetraploid $T$. durum. The results obtained with ABS ${ }^{1}$ combination indicate also what could be done with genes on the D genome of diploid $E$. squarrosa. Instead of attempting to produce colchicine doubled amphidiploids, squarrosa genes could be transferred to hexaploid $T$. astivum by securing AABBD pentaploid $F_{2}$ plants from a $T$. durum $\times A E$. squarrosa triploid and crossing them to hexaploid AABBDD T. astivum.

\section{SUMMARY}

I. Diploid to tetraploid introgression by means of interspecific triploid hybrids was followed in the wheat (Triticum-Egilops) group in two species combinations:

(i) T. durum $\times$ T. beoticum; (ii) T. durum $\times$ E. longissima .

2. In each combination triploid $F_{1}$ hybrids are not completely sterile. When exposed to massive back pollination by the tetraploid parents, triploids set occasional seed.

3. Analysis of the ensuing $\mathrm{F}_{2}$ and $\mathrm{F}_{3}$ derivatives gave the following results:

(i) When the diploid and the tetraploid species share one genome (durum $\times$ beoticum $\mathrm{AAB}$ genomic combination) reproductive barriers are effectively crossed by occasional production in the $\mathrm{F}_{1}$ triploids of balanced, roughly $n=\mathrm{I} 4 \mathrm{AB}$ types of female gametophytes.

(ii) when three different genomes constitute the triploid hybrid (durum $\times$ longissima $\mathrm{ABS}^{1}$ genomic combination) the disruptive effect of meiosis in the $F_{1}$ triploid is overcome by occasional formation of unreduced or almost unreduced $\mathrm{ABS}^{1}$ eggs. But in comparison to the first combination introgression here is a slower process.

4. Data indicate the operation in the wheat group of diploid to tetraploid introgression in nature. 
Acknowledgments.-Thanks are due to Miss Zohar Brick for the preparation of the triploid hybrids that started this study. The authors are greatly indebted to the Agricultural Research Service of the United States Department of Agriculture for a research grant (FG-Is-I29) which supported this study.

\section{REFERENCES}

FELDMAN, M. 1965. Further evidence for natural hybridization between tetraploid species of Egilops section Pleionathera. Evolution, 19, 162-1 74.

HARLAN, J. R. I 965 . The possible role of weed races in the evolution of cultivated plants. Euphytica, I4, I 73-I 76 .

KIHARA, H. I954. Considerations on the evolution and distribution of Egilops species based on the analyzer-method. Cytologia, 19, 336-357.

PAZY, B., AND zOHARY, D. I 965 . The process of introgression between Afilops polyploids: Natural hybridization between $A$. variabilis, $A$. ovata and $A$. biuncialis. Evolution, 19, 385-394.

SEARS, E. R. I959. Weizen I: The systematics, cytology and genetics of wheats. In Handbuch der Pflanzenzuechtung ed. H. Kappert, and W. Rudorf, Vol. II, I64-187. Parey, Berlin.

zOHARY, D. 1965. Colonizer species in the wheat group in The Genetics of Colonizing Species ed. H. G. Baker, and G. L. Stebbins, 404-420. Academic Press, New York.

zOHARY, D., AND FELDMAN, M. 1962. Hybridization between amphidiploids and the evolution of polyploids in the wheat (Egilops-Triticum) group. Evolution, ${ }_{16} 6$, $44-6$ I.

zOHARY, D., AND NUR, U. 1959. Natural triploids in the Orchard Grass, Dactylis glomerata L. polyploid complex and their significance for gene flow from diploid to tetraploid levels. Evolution, 13, 31 I-317.

\section{Note added in Proof}

Since the completion of this paper we have grown additional generations from the $\mathrm{ABS}^{1}$ durum $\times$ longissima combination. Among $\mathrm{F}_{4}$ and $\mathrm{F}_{5}$ plants derived from the $F_{2}$ AABBS $^{1}$ pentaploids we already detected four $2 n=42$ plants. These hexaploids were all fertile and showed more or less regular chromosome pairing in meiosis (most p.m.c.s had 2I bivalents). Thus in a matter of 2-3 generations $F_{2}$ pentaploids gave rise to stabilised AABBS ${ }^{1} \mathrm{~S}^{1}$ amphidiploids, and the process of increasing chromosome number was completed. 